\title{
Diverging effects of premature birth and bronchopulmonary dysplasia on exercise capacity and physical activity - a case control study
}

\author{
Katharina Ruf $^{1 *}\left(\mathbb{D}\right.$, Wolfgang Thomas $^{1,2}$, Maximilian Brunner ${ }^{1,3}$, Christian P. Speer $^{1}$ and Helge Hebestreit ${ }^{1}$
}

\begin{abstract}
Background: Extreme prematurity has been associated with exercise intolerance and reduced physical activity. We hypothesized that children with bronchopulmonary dysplasia (BPD) would be especially affected based on longterm lung function impairments. Therefore, the objective of this study was to compare exercise capacity and habitual physical activity between children born very and extremely preterm with and without BPD and term-born children.

Methods: Twenty-two school-aged children (aged 8 to 12 years) born with a gestational age $<32$ weeks and a birthweight $<1500 \mathrm{~g}$ (9 with moderate or severe BPD (=BPD), 13 without BPD (=No-BPD)) and 15 healthy termborn children (=CONTROL) were included in the study. Physical activity was measured by accelerometry, lung function by spirometry and exercise capacity by an incremental cardiopulmonary exercise test.

Results: Peak oxygen uptake was reduced in the BPD-group ( $83 \pm 11 \%$ predicted) compared to the No-BPD group (91 $\pm 8 \%$ predicted) and the CONTROL group ( $94 \pm 9 \%$ predicted). In a general linear model, variance of peak oxygen uptake was significantly explained by BPD status and height but not by prematurity $(p<0.001)$.

Compared to CONTROL, all children born preterm spent significantly more time in sedentary behaviour (BPD $478 \pm$ $50 \mathrm{~min}, \mathrm{No}-\mathrm{BPD} 450 \pm 52 \mathrm{~min}, \mathrm{CONTROL} 398 \pm 56 \mathrm{~min}, p<0.05)$ and less time in moderate-to-vigorous-physical activity (BPD $13 \pm 8 \mathrm{~min}, \mathrm{No}-\mathrm{BPD} 16 \pm 8 \mathrm{~min}$, CONTROL $33 \pm 16 \mathrm{~min}, p<0.001$ ). Prematurity but not BPD contributed significantly to explained variance in a general linear model of sedentary behaviour and likewise moderate-tovigorous-physical activity ( $p<0.05$ and $p<0.001$ respectively).

Conclusion: In our cohort, BPD but not prematurity was associated with a reduced exercise capacity at school-age. However, prematurity regardless of BPD was related to less engagement in physical activity and more time spent in sedentary behaviour. Thus, our findings suggest diverging effects of prematurity and BPD on exercise capacity and physical activity.
\end{abstract}

Keywords: Bronchopulmonary dysplasia, Physical activity, Exercise testing, Preterm birth, Exercise capacity, Sedentary behaviour

\footnotetext{
* Correspondence: ruf_k@ukw.de

${ }^{1}$ University Children's Hospital Würzburg, University of Würzburg,

Josef-Schneider-Str. 2, 97080 Würzburg, Germany

Full list of author information is available at the end of the article
}

C The Author(s). 2019 Open Access This article is distributed under the terms of the Creative Commons Attribution 4.0 International License (http://creativecommons.org/licenses/by/4.0/), which permits unrestricted use, distribution, and reproduction in any medium, provided you give appropriate credit to the original author(s) and the source, provide a link to the Creative Commons license, and indicate if changes were made. The Creative Commons Public Domain Dedication waiver (http://creativecommons.org/publicdomain/zero/1.0/) applies to the data made available in this article, unless otherwise stated. 


\section{Background}

Preterm birth has been associated with long-term sequelae such as pulmonary function impairment due to bronchopulmonary dysplasia (BPD) [1]. However, effects of prematurity on other outcomes such as exercise capacity are less clear and studies have provided conflicting results [2-8]. An important limitation of most studies was that children were included regardless of lung disease severity as BPD status and severity was rarely reported. Furthermore, the picture of BPD has changed over time.

The "classical" BPD described by Northway in 1967 was characterized by a diffuse and severe damage to the lung leading to focal hyperinflation and interstitial fibrosis [9]. With the introduction of antenatal steroids for lung maturation and surfactant therapy for respiratory distress syndrome in the 1990s, the pattern of defects has changed. This "new" BPD is characterised by changes in pulmonary vascularization and alveolarization based on an arrest of lung development [10, 11], which lead to impaired gas exchange and a possible need for supplemental oxygen in early infancy $[1,12]$. The new $\mathrm{BPD}$ is due to lower gestational age and lower birth weight together with pre- and postnatal factors such as chorioamnionitis, sepsis, mechanical ventilation, oxygen therapy and inflammation [12-14].

During childhood, BPD has been associated with bronchial obstruction and reduced diffusion capacity $[3,5,12,15]$. Lung function impairment may persist into adult age $[16,17]$. Thus, BPD affects health beyond the neonatal period and is relevant for long term outcome after extreme prematurity [16]. Given persisting impairments in lung function and alveolar vascularization in children with BPD born in the late 1990s and thereafter, a reduced exercise capacity can be hypothesized.

Similar to exercise capacity, existing data on physical activity in former preterm children show diverging results. Reduced physical activity has been reported in teens and adults who were born preterm at very low birthweight $[18$, 19], possibly related to constraints such as neuromotor, cognitive or airway abnormalities. Other studies, however, report no differences in objectively measured physical activity when comparing school-age children born preterm to term-born children $[3,20]$. The effects of BPD on physical activity have not been assessed yet. However, given the more pronounced and persistent pulmonary impairments in children born prematurely with BPD compared to those without BPD, we hypothesised limitations in physical activity especially in children with BPD.

To test our above hypotheses, this study assessed exercise capacity and objectively measured physical activity in children born extremely preterm with moderate or severe $B P D$ and without $B P D$ in comparison to term-born children.

\section{Materials and methods Study population}

All surviving preterm infants with a gestational age $<32$ completed weeks and a birth weight $<1500 \mathrm{~g}$ treated in our hospital in the years 1997 to 2001 were eligible for the study. 46 of these met the criteria of moderate or severe BPD as defined by Jobe and Bancalari [1]. For recruitment, a letter of invitation was sent to the latest available address. Finally, 10 children with moderate to severe BPD (BPD) and their legal guardians consented to participate. Of the same premature cohort, 15 children without BPD (No-BPD) were included in the study. Since twins were initially included in the BPD group and triplets in the No-BPD group and - according to the analysis plan - only the first-borns were chosen for analysis, 3 children were excluded. Recruitment details are shown in Fig. 1. Furthermore, 15 healthy children born at term between 1997 and 2001 with an uneventful neonatal period served as controls (CONTROL). These were friends or siblings of the included preterm children to reduce selection bias. At the time of assessment, participants were aged $7-12$ years.

\section{Study design}

The study was approved by the Ethics Committee of the Medical Faculty of the University of Würzburg (46/09). Verbal assent and written informed consent were obtained from participants and their legal guardians, respectively.

Participants came for one study visit to our hospital. After physical examination and taking anthropometric measures, the children completed lung function testing including spirometry, body plethysmography and assessment of diffusion capacity. Subsequently, after familiarizing the participants with the equipment, they performed an incremental exercise test on a cycle ergometer up to volitional fatigue.

Following the study visit, physical activity was continuously measured by accelerometry, which allowed objectively recording activity in a free-living environment.

\section{Assessment of physical activity by accelerometry}

Accelerometry took place for all participants in October and November 2009 to avoid bias due to seasonal variations of physical activity [21]. Study participants wore ActiGraph GT1M accelerometers (ActiGraph, Fort Walton Beach, Florida, USA). They were instructed to wear the device on the right hip for 9 consecutive days during waking hours and with the exception of water-related activities. Activity counts were averaged over a period of $15 \mathrm{~s}$ (epochs) and counts/minute were calculated from these data. A minimum recording time of $10 \mathrm{~h}$ on at least 3 week-days and 1 weekend-day was considered to yield valid data. Sedentary activity was defined as $\leq 100 \mathrm{cts} / \mathrm{min}$, light activity as $>100 \leq$ 
Preterm cohort 1997-2001: $<32$ weeks gestational age; $<1500 \mathrm{~g}$ birth weight

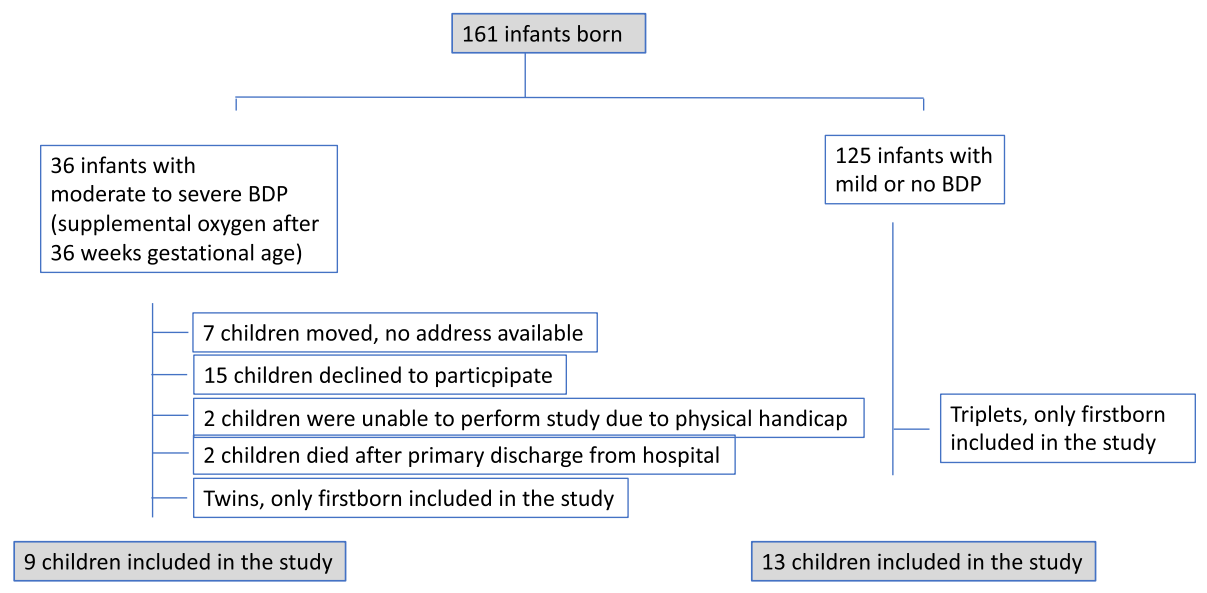

Fig. 1 Recruitment of participants

$1000 \mathrm{cts} / \mathrm{min}$. Time spent in moderate and vigorous physical activity (MVPA) was derived with the lower threshold for MVPA set at $3600 \mathrm{cpm}$ (equal to 4 metabolic equivalents of task (METs)), according to a calibration study with Caucasian children of similar age [22].

\section{Anthropometry}

Height was measured using a fixed stadiometer (Seca216, Seca, Hamburg, Germany). Weight was recorded in underwear to the nearest $0.1 \mathrm{~kg}$ using a digital scale (Seca701, Seca, Hamburg, Germany). Skinfold measurements were performed in triplicates at clearly defined sites (suprailiac, subscapular, over the biceps and over the triceps; Tanner/Whitehouse skinfold caliper, Holtain, Crymych, UK) and the median was used to estimate the children's fat free body mass [23].

\section{Physical examination, electrocardiography and echocardiography}

A complete medical history was taken including information on physician-diagnosed asthma, severe visual or hearing impairments or cerebral palsy. A thorough physical examination was conducted and a 12-lead electrocardiography (Custocard M, Customed, Ottobrunn, Germany) and echocardiography (VIVID 7-System, General Electric Healthcare, Milwaukee/WI, USA) were performed to identify contraindications against maximal exercise testing.

\section{Lung function testing}

The Jaeger MasterScreen System (CareFusion, Hoechberg, Germany) was used to measure spirometric data, static lung volumes, airway resistance and diffusing capacity for carbon monoxide (TLCO). Spirometry has been applied to assess forced expiratory volume in $1 \mathrm{~s}$ (FEV1) and forced vital capacity (FVC), which reflect a possible obstructive or restrictive airway disease. Likewise, static lung volumes were assessed using bodyplethysmography. Residual volume (RV) and total lung capacity (TLC) were analysed to gain information about restrictive airway disease or a possible hyperinflation. Especially, RV to TLC ratio (RV\%TLC) indicates a pulmonary hyperinflation. Specific airway resistance (SReff) has served as further marker of airway obstruction. Diffusion capacity (TLCOC) has been measured with the help of the diffusion capacity for carbon monoxide in the single breath technique $(10 \mathrm{~s}$ breath hold). All lung function testing was performed according to current standards [24], values are expressed as percent of predicted values $[25,26]$, limits of normal ranges were determined according to Pellegrino et al. [27].

Study participants did not use regular asthma medications and none of them used inhaled bronchodilators prior to lung function testing. As our study protocol precluded blood drawing, TLCO was not corrected for haemoglobin-concentrations. Further, exhaled nitric oxide (eNO) as a marker of eosinic inflammation was measured (Eco medical, Analyzer CLD 88 sp., Duernten, Switzerland).

\section{Exercise testing}

For cycle ergometry, a calibrated cycle ergometer (Ergoselect 200OK, Ergoline, Bitz, Germany) was used with the seat adjusted in horizontal and vertical position and the crank arm length modified so that the legs were bent not more than $90^{\circ}$ and not fully extended during cycling. All participants completed a previously published continuous incremental exercise test protocol [28]. The initial work rate was $7 \mathrm{~W}$ for $2 \mathrm{~min}$. It was increased to $1 \mathrm{~W} \cdot \mathrm{kg}^{-1}$ body weight for $2 \mathrm{~min}, 2 \mathrm{~W} \cdot \mathrm{kg}^{-1}$ body weight for another $2 \mathrm{~min}$ and then by $0.5 \mathrm{~W} \cdot \mathrm{kg}^{-1}$ body weight every minute up to 
volitional fatigue. A maximal effort was assumed if the subjects' appearance suggested maximal exertion and their heart rate was above 195/min and/or their respiratory exchange rate (RER) exceeded 1.03 [29].

Ventilatory and gas exchange parameters were measured breath-by-breath using a metabolic cart (CPX/D, MedGraphics). $\mathrm{VO}_{2}$ peak was taken as the highest $\mathrm{VO}_{2}$ over $30 \mathrm{~s}$ during the exercise test and expressed as \%predicted based on gender and height [29]. The workload (in Watt) of the last completed stage of the incremental test was equally transformed into \%predicted (maximal workload) [30].

\section{Statistical analysis}

Participants' characteristics are described by means and standard deviation as data was normally distributed. To assess differences in continuous variables among the three groups, ANOVA analyses were calculated. Posthoc t-tests with Bonferroni adjustments of $p$-values served to detect differences between the groups BPD, No-BPD, and CONTROL.

To assess influences of BPD and premature birth on exercise capacity and physical activity, general linear models were used. Peak oxygen uptake was set as dependent variables, height, premature birth (yes/no) and status of bronchopulmonary dysplasia (yes/no) were entered as independent variables. Likewise, time spent in sedentary behaviour or MVPA, respectively, were used as dependent variables with height, premature birth, and status of bronchopulmonary dysplasia as independent variables. Further, we tested body mass index (BMI) instead of height in a linear model as a possible marker for obesity when analysing sedentary behaviour. Effects of the respective variables on the model fit are reported as partial eta squared.

All statistical analyses were performed using SPSS version 25 (SPSS Inc., Chicago, USA). A $p$-value $<0.05$ was considered significant.

\section{Results}

The participants' characteristics are presented in Table 1. No differences were found among BPD, No-BPD and
CONTROL with regard to age, sex, heart rate at rest, blood pressure, height, weight or fat free body mass.

Data on the ante-and perinatal period are displayed in Table 2.

With regard to neurological long-term outcome (cerebral palsy, visual and hearing impairments) no significant differences were observed among the groups for any of these. This is also true for physician-diagnosed and parent-reported bronchial asthma (only one child in the No-BPD group was affected by bronchial asthma).

\section{Lung function}

Results of spirometry, airway resistance and diffusion capacity testing are presented in Table 3. Significant differences among groups were detected by ANOVA for forced expiratory volume in $1 \mathrm{~s}$ (FEV1\% predicted), specific effective airway resistance (SReff\% predicted) and the transfer factor of the lung for carbon monoxide (TLCO\% predicted). Results of posthoc testing are displayed in Table 4. Although FEV1 was significantly lower in BPD compared with CONTROL and SReff was higher in BPD compared to CONTROL and No-BPD, average values of the BPD group were still within the limits of the normal range. Diffusion capacity was reduced in both preterm groups (BPD and No-BPD). However, only BPD showed a mild average impairment with regard to normal values. Exhaled NO was within normal values in all three groups [31].

\section{Exercise capacity}

Results of exercise testing are presented in Table 5. All participants reached a maximal effort based on predefined criteria (see above). Maximal work rate (Wpeak) expressed in \% predicted did not differ between the groups. However, the groups differed significantly in peak oxygen uptake $(\mathrm{ml} / \mathrm{min})$, also when expressed in \% predicted. Posthoc testing showed a significant difference between CONTROL and BPD $(p<0.05)$, not between the other groups. In a general linear model, peak oxygen uptake was explained by height $(p<0.001$, eta squared 0.674) and BPD status $(p<0.05$, eta sqared

Table 1 Patients' characteristics

\begin{tabular}{|c|c|c|c|c|}
\hline & $\begin{array}{l}\mathrm{BPD} \\
n=9\end{array}$ & $\begin{array}{l}\text { No-BPD } \\
n=13\end{array}$ & $\begin{array}{l}\text { CONTROL } \\
n=15\end{array}$ & $p$-value \\
\hline Age (years) & $10.9 \pm 1.7$ & $10.4 \pm 1.5$ & $9.9 \pm 1.3$ & 0.22 \\
\hline Male (n (percentage of total)) & $4(40 \%)$ & $7(47 \%)$ & $8(53 \%)$ & 0.85 \\
\hline Heart rate (beats.min ${ }^{-1}$ ) & $83.9 \pm 8.4$ & $76.5 \pm 13.5$ & $82.7 \pm 14.7$ & 0.29 \\
\hline Mean blood pressure (mmHg) & $85.0 \pm 8.0$ & $84.2 \pm 11.4$ & $82.5 \pm 4.0$ & 0.74 \\
\hline Height (cm) & $140.2 \pm 11.0$ & $144.6 \pm 10.8$ & $140.2 \pm 9.5$ & 0.26 \\
\hline Weight (kg) & $32.6 \pm 11.9$ & $34.4 \pm 7.4$ & $31.7 \pm 6.6$ & 0.20 \\
\hline Fat free body mass (kg) & $25.4 \pm 5.8$ & $28.0 \pm 5.6$ & $26.4 \pm 5.2$ & 0.50 \\
\hline
\end{tabular}

Data are shown as number $(\mathrm{n})$ and percentage of total or mean \pm standard deviation 
Table 2 pre-and perinatal data

\begin{tabular}{|c|c|c|c|}
\hline & $\begin{array}{l}\mathrm{BPD} \\
n=9\end{array}$ & $\begin{array}{l}\text { No-BPD } \\
n=13\end{array}$ & $\begin{array}{l}\text { CONTROL } \\
n=15\end{array}$ \\
\hline Gestational age (weeks) & $26.6 \pm 1.6(24.6-29.7)$ & $29.1 \pm 1.8(25.0-31.0)$ & $39.3 \pm 0.9(38.0-41.0)$ \\
\hline Birthweight (g) & $766.7 \pm 212.4(450-1080)$ & $117.3 \pm 242.6(780-1440)$ & $3382.7 \pm 327.5(2800-3950)$ \\
\hline SGA (number of total/percent) & $3 / 9(33 \%)$ & $3 / 13(23 \%)$ & $3 / 15(20 \%)$ \\
\hline Antenatal steroids (number of total/percent) & $5 / 9(56 \%)$ & $7 / 13(54 \%)$ & 0 \\
\hline Surfactant (number of total/percent) & $8 / 9(89 \%)$ & $4 / 13(31 \%)$ & 0 \\
\hline \multicolumn{4}{|l|}{ Respiratory support } \\
\hline $\begin{array}{l}\text { Synchronized-intermittent-mandatory ventilation (SIMV) } \\
\text { Number of patients/days }\end{array}$ & $\begin{array}{l}9 / 9 \\
24.9 \pm 14.4(2-47)\end{array}$ & $\begin{array}{l}8 / 13 \\
3.7 \pm 5.3(0-19)\end{array}$ & $0 / 15$ \\
\hline High-frequency ventilation & $\begin{array}{l}4 / 9 \\
3.4 \pm 5.0(0-12)\end{array}$ & $0 / 13$ & $0 / 15$ \\
\hline Binasal continuous-positive-pressure ventilation (CPAP) & $27.8 \pm 9.5(14-40)$ & $7.1 \pm 5.1(0-20)$ & 0/15 \\
\hline
\end{tabular}

Data are mean \pm standard deviation (range), if not displayed otherwise

0.136 ), not by prematurity ( $p=0.906$, eta squared 0 ). BPD showed a significantly lower tidal volume at peak exercise while achieving the same minute ventilation in comparison to the other groups (see Table 5).

\section{Physical activity}

Results of accelerometry are presented in Fig. 2a and b. The CONTROL group spent significantly more time in MVPA than both preterm groups (Fig. 2a). No difference was observed between BPD and No-BPD. The amount of time spent in sedentary behaviour was significantly elevated in children born preterm (Fig. 2b). Again, there was no difference between BPD and No-BPD.

A general linear model for sedentary behaviour showed that although height had a significant impact on the model $(p<0.05$, eta squared 0.141$)$, prematurity further contributed significantly to explaining variance $(p<$ 0.05 , eta squared 0.123), whereas BPD status did not. When replacing height by BMI, only prematurity showed a significant influence on the model $(p<0.05$, eta squared 0.170 ).

Likewise, in a general linear model for MVPA only prematurity contributed to explaining variance $(p<0.001$, eta squared 0.315) while height and BPD status did not.

Table 3 Lung function parameters

\begin{tabular}{lllll}
\hline parameter & BPD & No-BPD & CONTROL & $p$-value \\
\hline FEV1 (\%pred) & $83 \pm 22$ & $97 \pm 11$ & $105 \pm 8$ & $\mathbf{0 . 0 0 2}$ \\
FVC (\%pred) & $95 \pm 17$ & $101 \pm 13$ & $106 \pm 7$ & 0.09 \\
RV\%TLC (\%pred) & $122 \pm 52$ & $109 \pm 32$ & $109 \pm 28$ & 0.664 \\
SReff (\%pred) & $204 \pm 98$ & $138 \pm 39$ & $120 \pm 43$ & $\mathbf{0 . 0 0 6}$ \\
TLCO (\%pred) & $75 \pm 16$ & $85 \pm 8$ & $92 \pm 11$ & $\mathbf{0 . 0 0 1}$ \\
eNO (ppb) & $9.7 \pm 6.4$ & $14.5 \pm 6.4$ & $5.4 \pm 5.3$ & $\mathbf{0 . 0 0 2}$ \\
\hline
\end{tabular}

Data are mean \pm standard deviation

Significant $p$-values are marked in boldface

\section{Discussion}

The major finding of this study was that BPD but not prematurity per se was associated with reduced exercise capacity. However, prematurity regardless of BPD was related to less engagement in physical activity and more time spent in sedentary behaviour at school-age.

In our cohort, BPD but not prematurity was linked to lower exercise capacity and decrements in lung function. A review analysing 22 studies on exercise capacity concluded that children born preterm have lower peak oxygen uptake and that those with BDP show the lowest values [32]. However, differences to term-born controls were rather small and the clinical relevance of this finding remains unclear. Still, reduced peak oxygen uptake may indicate constraints of gas exchange during exercise and suggests that preterm-born children, especially those with $\mathrm{BPD}$, need their ventilatory reserve to achieve equal or nearly equal peak oxygen uptake $[32,33]$. This is in line with our data, where the BPD group showed lower peak oxygen uptake and at the same time lower peak

Table 4 Posthoc testing results for significant differences in lung function testing

\begin{tabular}{lll}
\hline & & $p$-value \\
\hline FEV1 (\%pred) & CONTROL vs No-BPD & 0.349 \\
& CONTROL vs BPD & $\mathbf{0 . 0 0 1}$ \\
No-BPD vs BPD & 0.073 \\
& CONTROL vs No-BP & 1.0 \\
CONTROL vs BPD & $\mathbf{0 . 0 0 6}$ \\
TLCO (\%pred) & No-BPD vs BPD & $\mathbf{0 . 0 4 4}$ \\
& CONTROL vs No-BPD & $\mathbf{0 . 0 0 7}$ \\
& CONTROL vs BPD & $<\mathbf{0 . 0 0 1}$ \\
& No-BPD vs BPD & 0.121 \\
\hline
\end{tabular}

Results are $p$-values of posthoc Bonferroni-testing after comparing groups using ANOVA

Significant $p$-values are marked in boldface 
Table 5 Results of exercise testing

\begin{tabular}{lllll}
\hline parameter & BPD & No-BPD & CONTROL & $p$-value \\
\hline VO2peak (ml/min) & $1292 \pm 343$ & $1649 \pm 388$ & $1508 \pm 243$ & 0.050 \\
VO2peak (\%pred) & $83 \pm 11$ & $91 \pm 8$ & $94 \pm 9$ & $\mathbf{0 . 0 2 4}$ \\
Wpeak (\% pred) & $97 \pm 18$ & $112 \pm$ & $112 \pm 15$ & 0.088 \\
Peak heart rate (/min) & $196 \pm 8$ & $197 \pm 7$ & $197 \pm 7$ & 0.79 \\
Peak SpO2, (\%) & $97.8 \pm 2$ & $98.1 \pm 3$ & $99.0 \pm 1$ & 0.20 \\
RERpeak & $1.05 \pm 0$ & $1.13 \pm 0$ & $1.08 \pm 0$ & 0.43 \\
Vtpeak (ml) & $782 \pm 199$ & $1108 \pm 2829$ & $980 \pm 313$ & $\mathbf{0 . 0 3 6}$ \\
VEpeak (I/min) & $46 \pm 12$ & $58 \pm 17$ & $52 \pm 9$ & 0.21 \\
\hline
\end{tabular}

Data are mean \pm standard deviation

Significant $p$-values are marked in boldface

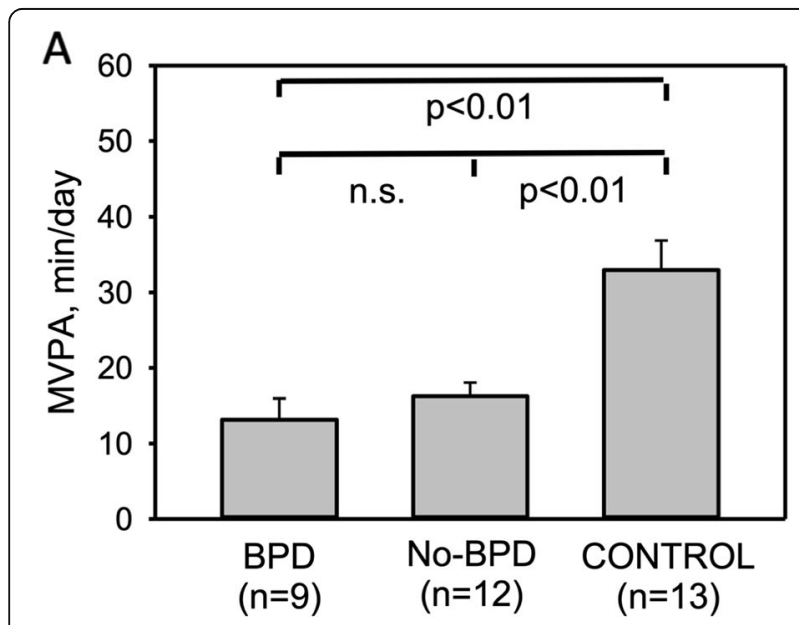

B

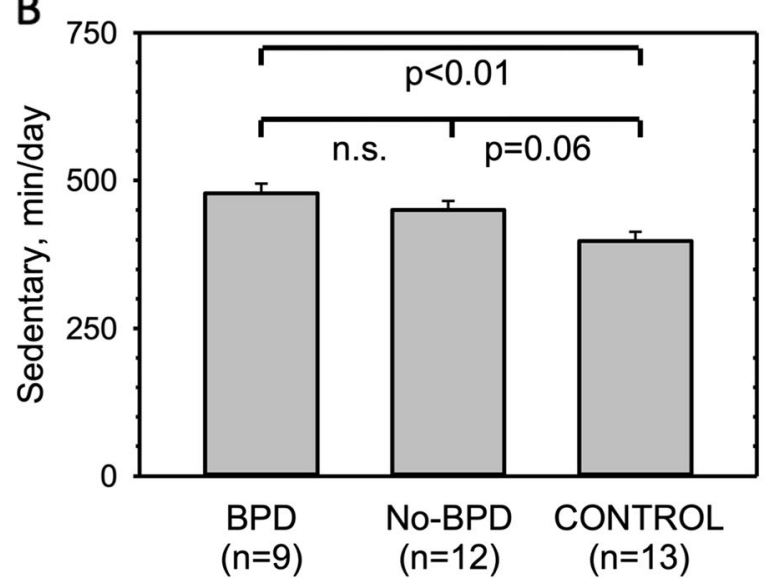

Fig. 2 Time spent in two physical activity levels per day as determined from accelerometry in BPD, No-BPD and CONTROL, a) Moderate-to-vigorous physical activity, b) Sedentary behaviour, Columns represent minutes spent in the respective activity level per day. Data are means plus standard errors. ANOVA showed significant differences among groups for both activity levels (moderate-tovigorous activity $p<0.001$; sedentary behaviour $p=0.004$ ). Between group differences displayed are based on posthoc test analyses tidal volume, possibly reflecting altered breathing mechanisms. There is ample evidence that children born preterm show decrements in lung function (reduced FEV1, FVC, TLCO) $[17,34]$ and those with BPD are affected even more $[16,17,35,36]$, which may result in reduced exercise capacity [37]. We also observed an impairment in diffusion capacity in the BPD and the No-BPD groups. However, a mild impairment of diffusion capacity did not have any effect on exercise capacity in normoxia and even hypoxia in adults born extremely preterm [15]. Nevertheless, we cannot exclude that the lower diffusion capacity which was most evident in the BPD group contributed to the reduced exercise capacity.

In our cohort, prematurity was related to significantly less moderate-to-vigorous physical activity (MVPA). One of the few reports on physical activity of people born preterm found a significantly lower leisure time activity in otherwise unimpaired adults born preterm and healthy adults [18]. In contrast, other studies reported no difference between preterm and term-born children in physical activity behaviour assessed by questionnaires [38] or accelerometry [3, 20]. In one of the mentioned accelerometry studies, epoch time had been set to $60 \mathrm{~s}$ [3], for the other study epoch time is not reported [20]; therefore, short activity bouts typical for children might have been missed. In the Epicure study [3] which used the same MVPA cut-offs as we did, both groups, preterm and term-born children spent very little time in MVPA (9 vs $11 \mathrm{~min}$ per day). As the term-born group spent far less time in MVPA compared to other studies on healthy individuals, it may be hypothesized that the comparable MVPA between preterm and term-born children in the Epicure study was due to an unusually poor MVPA in the term-born children rather than a "normal" unimpaired MVPA in the preterm group. Another study with the same MVPA cut-offs reported 25 and $19 \mathrm{~min}$ (boys and girls) spent in MVPA per day in children born 25-32 weeks' gestation compared to 27 and $16 \mathrm{~min}$ (boys and girls) in term-born children [20]. Compared to this study, children born preterm of our cohort spent less time in MVPA with an average of 15 min, however, term-born controls were more active as they spent $33 \mathrm{~min}$ in MVPA. Spending about half an hour in MVPA per day is in line with activity reported for healthy children [39]. Due to the small sample size we did not perform a gender-specific analysis. However, since there was no difference in gender distribution among groups, the effects observed in this study cannot be attributed to a gender selection bias.

Few studies assessed sedentary behaviour, although it has been depicted as a further independent risk factor for obesity and its sequelae [40]. Since prematurity itself is associated with a risk to acquire high blood pressure, lower bone mineral density and impaired glucose 
tolerance [41-43], sedentary behaviour may further increase these risks. On the other hand, regular physical exercise has been shown to reduce cardiovascular risk factors, especially in adults with low birthweight [44]. To our knowledge, only one study previously assessed inactivity in children born < 32 weeks' gestation [45] and reported $14 \mathrm{~min} /$ day of additional sedentary behaviour compared to term-born children. However, this difference was not significant. The present study is in line with these findings and is the first to describe a significant difference between term-born children and preterm-born children in sedentary behaviour.

Reduced engagement in physical activity of children born preterm might be of multifactorial origin. Altered breathing mechanisms with an earlier sensation of dyspnoea $[5,32,46,47]$ may lead to refrain from strenuous exercise. Further factors have been identified to affect activity behaviour. Sex, health problems, motor competence and hyperactivity influenced activity behaviour in a cohort of 12- to 20-year-olds born preterm [48]. Adults born at extremely or very low birth weight tend to have less physical self-confidence and a poorer physical coordination $[19,49,50]$. Besides poorer strength, flexibility and motor coordination in seemingly unimpaired adolescents born with extremely low birthweight [19], clumsiness may further lead to lower physical selfconfidence and consequently to refraining from regular physical activity. One recent study showed that developmental coordination disorder is much more common than thought and is often underreported by parents [51]. Whether parental overprotection may also lead to less engagement in physical activity needs yet to be clarified.

The strength of this study is that objectively measured physical activity data was generated through accelerometry with $15 \mathrm{~s}$ epochs to catch sporadic, short bouts of physical activity typical for children's play. Most studies used questionnaires to assess activity behaviour; these, however, tend to overestimate activity while at the same time recalling short, intense bouts of activity is difficult for children [52, 53]. Recall bias therefore impairs valid activity data from questionnaires $[20,54]$.

\section{Limitations}

Limitations of this study are the small sample size, a possible selection bias and the choice of cut-offs for physical activity assessment. Of the invited 36 children with moderate to severe BPD, consent became available for 10 children while no consent was given for 15 children. It may, thus, be speculated that only those with a certain interest in physical activity took part and that these may be the fitter and more active children of this cohort. However, this hypothesis would imply that the real impairments in BPD in exercise capacity and physical activity are even larger than observed in our study.

Activity of all participants was measured using the same cut-off for MVPA. The choice of cut-offs and whether cut-offs should be age-, gender-, height- or weight-specific is constantly under discussion. Since in our cohort, groups did not show significant differences in height, weight and age, the same cut-offs for all participants were chosen, which also enabled us to compare our data to existing research. Further, the accelerometer is worn on the hip which may impair the recording of certain activities. Especially cycling, a popular activity in children, is underestimated with this kind of measurement. As this is similar for all participants, though, we do not believe that this aspect relevantly distorts our results.

Since this is a single centre study focussing on the new BPD era, we have little bias regarding treatment during the neonatal period. Further, only children with moderate and severe BPD were included to clearly distinguish between children born premature with and without BPD.

\section{Conclusions}

According to our results, children with BPD show impaired exercise tolerance, probably due to constraints in lung function. Prematurity itself seems to predispose for reduced engagement in physical activity and a preference for sedentary behaviour. Further research is needed to determine the mechanisms of this behaviour and to analyse whether physical activity intervention programs are feasible and effective to countervail reduced physical activity and increased sedentary behaviour and their negative effects.

\section{Abbreviations}

BPD: bronchopulmonary dysplasia / children born preterm with moderate or severe bronchopulmonary dysplasia; CONTROL: term-born children;

eNO: exhaled nitric oxide; FEV1: forced expiratory capacity in one second; FVC: forced vital capacity; MET: metabolic equivalent of task;

MVPA: moderate to vigorous physical activity; No-BPD: children born preterm without bronchopulmonary dysplasia; RER: respiratory exchange ratio; RV/TLC : residual volume to total lung capacity ratio; SReff: specific effective airway resistance; TLCOC: lung diffusion capacity for carbon monoxide;

VE: ventilated volume in one minute; VO2peak: peak oxygen uptake; Vt: tidal volume; Wmax: peak work load in Watt

\section{Acknowledgements}

The authors thank Imme Haubitz, PhD, for the help with the statistical analyses.

\section{Authors' contributions}

The study design was planned by $\mathrm{WT}$ and $\mathrm{HH}$. The study was conducted by WT and MB with the help of $\mathrm{HH}$ and KR. Data of exercise testing and accelerometry were evaluated by $M B, H H$ and $K R$. Statistical analyses were performed by $W T, M B, K R$ and $H H$. The primary manuscript was drafted by WT. KR, CPS, and HH critically revised the manuscript. All authors read and approved the final manuscript.

\section{Funding}

This study was funded with 3000 Euro provided by KiWi e.V., an initiative to support the work of NICU and PICU at the University Children's hospital of Würzburg. The money was used to cover the participants' expenses. Further, this publication was funded by the German Research Foundation (DFG) and 
the University of Wuerzburg in the funding programme Open Access Publishing.

\section{Availability of data and materials}

The datasets used and analysed in this study are available from the corresponding author upon reasonable request.

\section{Ethics approval and consent to participate}

The study was approved by the local ethics committee (46/09). All participants and their legal guardians gave verbal assent and written informed consent.

\section{Consent for publication}

With signing the consent form, participants and their legal guardians agreed to anonymized publication of their data in scientific talks and papers.

\section{Competing interests}

The authors declare that they have no competing interests.

\section{Author details}

${ }^{1}$ University Children's Hospital Würzburg, University of Würzburg, Josef-Schneider-Str. 2, 97080 Würzburg, Germany. ${ }^{2}$ Abteilung für Kinder- und Jugendmedizin, Klinikum Mutterhaus der Borromäerinnen, Feldstr. 16, 54290 Trier, Germany. ${ }^{3}$ Klinik für Allgemein- und Viszeralchirurgie, Universitätsklinikum Erlangen, Krankenhausstraße 12, 91054 Erlangen, Germany.

\section{Received: 29 July 2019 Accepted: 11 November 2019}

\section{Published online: 21 November 2019}

\section{References}

1. Jobe AH, Bancalari E. Bronchopulmonary dysplasia. Am J Respir Crit Care Med. 2001;163:1723-9.

2. Clemm HH, Vollsaeter M, Roksund OD, Eide GE, Markestad T, Halvorsen T. Exercise capacity after extremely preterm birth. Development from adolescence to adulthood. Ann Am Thorac Soc. 2014:11:537-45.

3. Welsh L, Kirkby J, Lum S, Odendaal D, Marlow N, Derrick G, Stocks J, Group EPS. The EPICure study: maximal exercise and physical activity in school children born extremely preterm. Thorax. 2010;65:165-72.

4. Malleske DT, Chorna O, Maitre NL. Pulmonary sequelae and functional limitations in children and adults with bronchopulmonary dysplasia. Paediatr Respir Rev. 2018;26:55-9.

5. MacLean JE, DeHaan K, Fuhr D, Hariharan S, Kamstra B, Hendson L, Adatia I, Majaesic C, Lovering AT, Thompson RB, et al. Altered breathing mechanics and ventilatory response during exercise in children born extremely preterm. Thorax. 2016;71:1012-9.

6. Narang I, Bush A, Rosenthal M. Gas transfer and pulmonary blood flow at rest and during exercise in adults 21 years after preterm birth. Am J Respir Crit Care Med. 2009;180:339-45.

7. Kriemler S, Keller H, Saigal S, Bar-Or O. Aerobic and lung performance in premature children with and without chronic lung disease of prematurity. Clin J Sport Med. 2005;15:349-55.

8. Clemm H, Roksund O, Thorsen E, Eide GE, Markestad T, Halvorsen T. Aerobic capacity and exercise performance in young people born extremely preterm. Pediatrics. 2012;129:e97-e105.

9. Northway WH Jr, Rosan RC, Porter DY. Pulmonary disease following respirator therapy of hyaline-membrane disease. Bronchopulmonary dysplasia. N Engl J Med. 1967;276:357-68.

10. Husain AN, Siddiqui NH, Stocker JT. Pathology of arrested acinar development in postsurfactant bronchopulmonary dysplasia. Hum Pathol. 1998;29:710-7.

11. Thebaud B. Angiogenesis in lung development, injury and repair: implications for chronic lung disease of prematurity. Neonatology. 2007;91:291-7.

12. Hwang JS, Rehan VK. Recent advances in Bronchopulmonary dysplasia: pathophysiology, prevention, and treatment. Lung. 2018;196:129-38.

13. Groneck P, Gotze-Speer B, Oppermann M, Eiffert H, Speer CP. Association of pulmonary inflammation and increased microvascular permeability during the development of bronchopulmonary dysplasia: a sequential analysis of inflammatory mediators in respiratory fluids of high-risk preterm neonates. Pediatrics. 1994;93:712-8.
14. Thomas W, Speer CP. Chorioamnionitis: important risk factor or innocent bystander for neonatal outcome? Neonatology. 2011;99:177-87.

15. Duke JW, Elliott JE, Laurie SS, Beasley KM, Mangum TS, Hawn JA, Gladstone $I M$, Lovering AT. Pulmonary gas exchange efficiency during exercise breathing normoxic and hypoxic gas in adults born very preterm with low diffusion capacity. J Appl Physiol (1985). 2014;117:473-81.

16. Davidson LM, Berkelhamer SK. Bronchopulmonary dysplasia: chronic lung disease of infancy and long-term pulmonary outcomes. J Clin Med. 2017;6.

17. Um-Bergstrom P, Hallberg J, Pourbazargan M, Berggren-Brostrom E, Ferrara G, Eriksson MJ, Nyren S, Gao J, Lilja G, Linden A, et al. Pulmonary outcomes in adults with a history of Bronchopulmonary dysplasia differ from patients with asthma. Respir Res. 2019;20:102.

18. Kajantie E, Strang-Karlsson S, Hovi P, Raikkonen K, Pesonen AK, Heinonen K, Jarvenpaa AL, Eriksson JG, Andersson S. Adults born at very low birth weight exercise less than their peers born at term. J Pediatr. 2010;157:610-6 616 e611.

19. Rogers M, Fay TB, Whitfield MF, Tomlinson J, Grunau RE. Aerobic capacity, strength, flexibility, and activity level in unimpaired extremely low birth weight $(<0 r=800 \mathrm{~g})$ survivors at 17 years of age compared with term-born control subjects. Pediatrics. 2005;116:e58-65.

20. Lowe J, Watkins WJ, Kotecha SJ, Edwards MO, Henderson AJ, Kotecha S. Physical activity in school-age children born preterm. J Pediatr. 2015;166:877-83.

21. Riddoch CJ, Mattocks C, Deere K, Saunders J, Kirkby J, Tilling K, Leary SD, Blair SN, Ness AR. Objective measurement of levels and patterns of physical activity. Arch Dis Child. 2007;92:963-9.

22. Mattocks C, Leary S, Ness A, Deere K, Saunders J, Tilling K, Kirkby J, Blair SN, Riddoch C. Calibration of an accelerometer during free-living activities in children. Int J Pediatr Obes. 2007;2:218-26.

23. Slaughter MH, Lohman TG, Boileau RA, Horswill CA, Stillman RJ, Van Loan MD, Bemben DA. Skinfold equations for estimation of body fatness in children and youth. Hum Biol. 1988;60:709-23.

24. Miller MR, Hankinson J, Brusasco V, Burgos F, Casaburi R, Coates A, Crapo R, Enright P, van der Grinten CP, Gustafsson P, et al. Standardisation of spirometry. Eur Respir J. 2005;26:319-38.

25. Quanjer PH, Stanojevic S, Cole TJ, Baur X, Hall GL, Culver BH, Enright PL, Hankinson JL, Ip MS, Zheng J, et al. Multi-ethnic reference values for spirometry for the 3-95-yr age range: the global lung function 2012 equations. Eur Respir J. 2012;40:1324-43.

26. Stanojevic S, Graham BL, Cooper BG, Thompson BR, Carter KW, Francis RW, Hall GL. Global lung function initiative Twg, global lung function initiative T: official ERS technical standards: global lung function initiative reference values for the carbon monoxide transfer factor for Caucasians. Eur Respir J. 2017;50.

27. Pellegrino R, Viegi G, Brusasco V, Crapo RO, Burgos F, Casaburi R, Coates A, van der Grinten CP, Gustafsson P, Hankinson J, et al. Interpretative strategies for lung function tests. Eur Respir J. 2005;26:948-68.

28. Hebestreit $H$, Staschen B, Hebestreit A. Ventilatory threshold: a useful method to determine aerobic fitness in children? Med Sci Sports Exerc. 2000;32:1964-9.

29. Orenstein DM. Assessment of Exercise \& Pulmonary Function. In: TWR, editor. Pediatric Laboratory Exercise Testing. Champaign, IL, Human Kinetics; 1993. p. 141-63.

30. Godfrey S, Davies CT, Wozniak E, Barnes CA. Cardio-respiratory response to exercise in normal children. Clin Sci. 1971;40:419-31.

31. Buchvald F, Baraldi E, Carraro S, Gaston B, De Jongste J, Pijnenburg MW Silkoff PE, Bisgaard H. Measurements of exhaled nitric oxide in healthy subjects age 4 to 17 years. J Allergy Clin Immunol. 2005;115:1130-6.

32. Edwards MO, Kotecha SJ, Lowe J, Watkins WJ, Henderson AJ, Kotecha S. Effect of preterm birth on exercise capacity: a systematic review and metaanalysis. Pediatr Pulmonol. 2015;50:293-301.

33. Joshi S, Powell T, Watkins WJ, Drayton M, Williams EM, Kotecha S. Exerciseinduced bronchoconstriction in school-aged children who had chronic lung disease in infancy. J Pediatr. 2013;162:813-8 e811.

34. Clemm HH, Engeseth M, Vollsaeter M, Kotecha S, Halvorsen T. Bronchial hyper-responsiveness after preterm birth. Paediatr Respir Rev. 2018;26:34-40.

35. Fakhoury KF, Sellers C, Smith EO, Rama JA, Fan LL. Serial measurements of lung function in a cohort of young children with bronchopulmonary dysplasia. Pediatrics. 2010;125:e1441-7.

36. Fawke J, Lum S, Kirkby J, Hennessy E, Marlow N, Rowell V, Thomas S, Stocks J. Lung function and respiratory symptoms at 11 years in children born extremely preterm: the EPICure study. Am J Respir Crit Care Med. 2010;182:237-45.

37. Bolton CE, Bush A, Hurst JR, Kotecha S, McGarvey L. Lung consequences in adults born prematurely. Thorax. 2015;70:574-80. 
38. Nordvall-Lassen M, Hegaard HK, Obel C, Lindhard MS, Hedegaard M, Henriksen TB. Leisure time physical activity in 9- to 11-year-old children born moderately preterm: a cohort study. BMC Pediatr. 2018;18:163.

39. Smith MP, Berdel D, Nowak D, Heinrich J, Schulz H. Physical activity levels and domains assessed by Accelerometry in German adolescents from GINIplus and LISAplus. PLoS One. 2016;11:e152217.

40. Mitchell JA, Mattocks C, Ness AR, Leary SD, Pate RR, Dowda M, Blair SN, Riddoch C. Sedentary behavior and obesity in a large cohort of children. Obesity (Silver Spring). 2009;17:1596-602.

41. Doyle LW, Faber B, Callanan C, Morley R. Blood pressure in late adolescence and very low birth weight. Pediatrics. 2003;111:252-7.

42. Kaijser M, Bonamy AK, Akre O, Cnattingius S, Granath F, Norman M, Ekbom A. Perinatal risk factors for diabetes in later life. Diabetes. 2009;58:523-6.

43. Hovi P, Andersson S, Jarvenpaa AL, Eriksson JG, Strang-Karlsson S, Kajantie E, Makitie O. Decreased bone mineral density in adults born with very low birth weight: a cohort study. PLoS Med. 2009;6:e1000135.

44. Laaksonen DE, Lakka HM, Lynch J, Lakka TA, Niskanen L, Rauramaa R, Salonen JT, Kauhanen J. Cardiorespiratory fitness and vigorous leisure-time physical activity modify the association of small size at birth with the metabolic syndrome. Diabetes Care. 2003;26:2156-64.

45. Lowe J, Watkins WJ, Kotecha SJ, Kotecha S. Physical activity and sedentary behavior in preterm-born 7-year old children. PLoS One. 2016;11:e155229.

46. Karila C, Saulnier JP, Elie C, Taupin P, Scheinmann P, Le Bourgeois M, Waernessycle $\mathrm{S}$, de Blic J. exercise alveolar hypoventilation in long-term survivors of bronchopulmonary dysplasia. Rev Mal Respir. 2008;25:303-12.

47. Lovering AT, Elliott JE, Laurie SS, Beasley KM, Gust CE, Mangum TS, Gladstone IM, Duke JW. Ventilatory and sensory responses in adult survivors of preterm birth and bronchopulmonary dysplasia with reduced exercise capacity. Ann Am Thorac Soc. 2014;11:1528-37.

48. Proulx K, Majnemer A, Dahan-Oliel N, Mazer B, Nadeau L, Vanier K, Maltais DB. Factors associated with moderate to vigorous physical activity in adolescents born preterm. Pediatr Exerc Sci. 2017;29:260-7.

49. Burns YR, Danks M, O'Callaghan MJ, Gray PH, Cooper D, Poulsen L, Watter P. Motor coordination difficulties and physical fitness of extremely-lowbirthweight children. Dev Med Child Neurol. 2009:51:136-42.

50. Saigal S, Stoskopf B, Boyle M, Paneth N, Pinelli J, Streiner D, Goddeeris J. Comparison of current health, functional limitations, and health care use of young adults who were born with extremely low birth weight and normal birth weight. Pediatrics. 2007;119:e562-73.

51. Bolk J, Faroogi A, Hafstrom M, Aden U, Serenius F. Developmental coordination disorder and its association with developmental comorbidities at 6.5 years in apparently healthy children born extremely preterm. JAMA Pediatr. 2018;172:765-74.

52. Ward DS, Evenson KR, Vaughn A, Rodgers AB, Troiano RP. Acceleromete use in physical activity: best practices and research recommendations. Med Sci Sports Exerc. 2005;37:S582-8.

53. Adamo KB, Prince SA, Tricco AC, Connor-Gorber S, Tremblay M. A comparison of indirect versus direct measures for assessing physical activity in the pediatric population: a systematic review. Int J Pediatr Obes. 2009:4:2-27.

54. Shephard RJ. Limits to the measurement of habitual physical activity by questionnaires. Br J Sports Med. 2003;37:197-206 discussion 206.

\section{Publisher's Note}

Springer Nature remains neutral with regard to jurisdictional claims in published maps and institutional affiliations.

Ready to submit your research? Choose BMC and benefit from:

- fast, convenient online submission

- thorough peer review by experienced researchers in your field

- rapid publication on acceptance

- support for research data, including large and complex data types

- gold Open Access which fosters wider collaboration and increased citations

- maximum visibility for your research: over $100 \mathrm{M}$ website views per year

At BMC, research is always in progress.

Learn more biomedcentral.com/submissions 